\title{
Pain assessment in intensive care: who puts pen to paper?
}

\author{
H Laycock, H Wordsworth, \\ Pan-London Peri-operative Research and Audit Network (PLAN) and South East Anaesthetic Research CHain \\ (SEARCH)
}

From ESICM LIVES 2015

Berlin, Germany. 3-7 October 2015

\section{Introduction}

Pain is common in intensive care units (ICUs) [1]. Regular pain assessment can improve patient satisfaction and clinical outcomes. It is commonly performed by nurses [2], yet physician-led assessment can improve analgesic management. Using pain documentation as a surrogate for assessment, a review showed physiological parameters i.e. cardiovascular assessment, were more frequently documented by doctors than pain in critically ill patients [3].

\section{Objectives}

Review pain documentation in ICU.

\section{Methods}

An observational audit of adult ICU patients was conducted by trainee research networks (London and South East England). Governance approval was obtained at each hospital. Data collection was performed over two 24-hour periods (each representing a patient "episode"), with patients contributing data to either one or both periods. Medical and nursing notes were reviewed for pain and physiological parameter assessment and demographic data.

\section{Results}

44 ICU's participated (including medical, surgical and specialist units). 1022 patient episodes were reviewed, contributing 2463 separate patient assessments conducted by 412 doctors. 712 separate patients were included (mean age 61.8 years, range 19-103 years). Patients were intubated in $38 \%$ of patient episodes (unable to self report).

\section{Nursing Assessments}

$29 \%$ of patient episodes had no nursing pain assessment. Pain assessment for both sedated and awake patients, commonly used a $0-3$ scale $(52 \%)$ or the numerical rating scale (19\%). $0.02 \%$ of nursing pain assessments used validated assessment tools for sedated patients i.e. the Behavioural Pain Score or Critical-Care Pain Observation Tool.

\section{Doctor Assessment}

$79 \%$ of patient assessments documented by doctors included a cardiovascular system (CVS) review compared with $21 \%$ for pain. Of those pain assessments made, $89 \%$ described pain in terms of comfort or stability whilst $9 \%$ used a pain assessment tool.

\section{Conclusions}

This large data set represents practice occurring in ICUs in South East England and London. Whilst pain poses significant physiological and psychological consequences for the critically ill, our results suggest a sizeable proportion lacked any pain assessment. Nursing assessment often used non-validated tools for patients unable to selfreport. Doctors' documented CVS reviews 3 times more often than pain. Pain, when reported was mostly narrative. Authors recognise limitations include that a lack of documentation does not exclude an assessment, but believe it is a useful surrogate when evaluating patient care from charts. Our data raises a number of themes including whether doctors prioritise pain and the use of appropriate pain assessment tools in ICU. Does omission of pain documentation represent an assumption that pain management lies outside the remit of the doctor role, or perhaps reflects a lack of education? 


\title{
Acknowledgement
}

Dr F Rubulotta and Dr C Bantel.

Published: 1 October 2015

\author{
References \\ 1. Payen : 2007. \\ 2. Gelinas : 2004 \\ 3. Laycock : 2015.
}

doi:10.1186/2197-425X-3-S1-A328

Cite this article as: Laycock et al:: Pain assessment in intensive care:

who puts pen to paper? Intensive Care Medicine Experimental 2015

3(Suppl 1):A328.

\section{Submit your manuscript to a SpringerOpen ${ }^{\mathcal{D}}$ journal and benefit from:}

- Convenient online submission

- Rigorous peer review

- Immediate publication on acceptance

- Open access: articles freely available online

- High visibility within the field

- Retaining the copyright to your article

Submit your next manuscript at $\gg$ springeropen.com 